\section{International Trade and Investment Impact on Global Health}

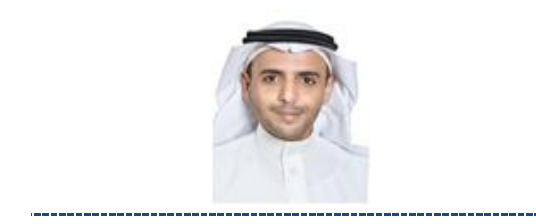

\author{
Hamza E. Albaheth
}

Email:halbaheth@tu.edu.sa Tel:+966550744550
Global Journal of Social Sciences Studies

Vol. 7, No. 2, 50-57, 2021

e-ISSN: 2518-0614

check for
updates

Assistant ProfessorShari'ah and Law School, Taif University, Saudi Arabia.

\begin{abstract}
Dealing with issues related to global health need the trade and investment laws. The global health is affected by the International Trade and Investment agreements or TIAs. It can have advantages on the factor like individuals and their wellbeing but, from the perspectives of social good and health range, also has some negative outcomes. This article emphasised on the changing the perspective towards contextual framework of public health and International Trade and Investment agreements or TIAs. There are a range of both positive and negative outcomes related to TIAs. They impact main health determinants in complex ways, for instance inequality and poverty and can elevate the inequalities factors within and between the nations. By analysing the highlighted issues, it has been suggested to re-structure the basic TIAs structure, as executed by the outlined comprehensive approach.
\end{abstract}

Keywords: International trade, Investment, Global helth, Investment agreement, World trade orgnisation.

DOI: $10.20448 / 807.7 .2 .50 .57$

Citation | Hamza E. Albaheth (2021). International Trade and Investment Impact on Global Health. Global Journal of Social Sciences Studies, 7(2): 50-57.

Copyright: This work is licensed under a Creative Commons Attribution 3.0 License

Funding: This study received no specific financial support.

Competing Interests: The author declares that there are no conflicts of interests regarding the publication of this paper.

History: 30 August 2021/ Revised: 24 September 2021/ Accepted: 15 October 2021/ Published: 4 November 2021

Publisher: Online Science Publishing 


\section{Highlights of this paper}

- This article contributes to the existing literature in highlightingthe on the impact of international trade and its legal treaties on global health.

- In addition, the article explains the linking the investment benefit with the general requirements of society, such as the requirements of public health.

- Furthermore, the article defines a new role for multiple investment agreements in global health.

- Finally, the article highlights the possibility of modifying the structure of the global investment framework and its treaties to embrace supportive and development programs for poor communities.

\section{INTRODUCTION}

The international law leading the investment and trade at international level is a central to the independent economies' (like United Kingdom's) workings (Puig, 2015). With their neighbours, approximately every nation has trade and investment terms. Trade and investment agreements are massively available. Still the international trade and investment law has the impact on the economic sphere and for the global issues' resolution is considered as the main element. For explained issues related to the global warming cannot be solved effectively without reference to the disciplines of trade and investments. Even dealing with issues related to global health need the trade and investment laws. The global health is affected by the International Trade and Investment agreements or TIAs. It can have advantages on the factor like individuals and their wellbeing but, from the perspectives of social good and health range, also has some negative outcomes. This article will emphasis on the changing the perspective towards contextual framework of public health and International Trade and Investment agreements or TIAs. Due to its future focus nature and word count limitation, the material in the discussion part will provide a summary of the reason why change is required. For this particular article TIAs related to the international investment law and trade law will be explained with the incorporation of global health. The common goods horizon has become so broad that it will not be limited to the public goods only (Canton, 2021). Trade of products and services are governed by the international trade law and can be secured. In these domains, there is a wide range of TIAs along with the multilateral agreement policies which are cautiously administrated by the World Trade Organisation (WTO) and other regional and bilateral agreements outside the framework of WTO usually referred to as free trade agreements (FTAs)(Canton, 2021).

While this article illustrates different ways in which TIAs should change and progress in order to determine the objectives related to health and society, it will be acknowledged that giving impact to these changes would need a philosophical shift which would be fund AH-023 mental in the investment law and international trade law. This article will endeavour to provide some guidelines for the procedures and structures of TIAs that are proposed to be effective for not only government institutes but for non-government organisations while negotiating and rethinking the TIAs. It will not, though, provide measures for attaining proposed changes.

The following part will highlight the public health issues that were developed by TIAs in their broader corporate, global and legal contexts briefly. Then in the discussion part, a framework and principles will be proposed to address these highlighted issues.

\subsection{TIAs: Public Health Issues Related to these Agreements}

There are a range of both positive and negative outcomes related to TIAs. They impact main health determinants in complex ways, for instance inequality and poverty and can elevate the inequalities factors within and between the nations (McNamara \& Labonté, 2017). Precisely, TIAs has different implications for budgets of states governance of state; attaining objectives of developing nations and precise concerns related to health with regards to both communicable disease as well as no communicable disease or NCDs. 


\subsection{Budgets of State}

State budgets are affected by TIAs due to the reduction in tariff precisely for the developing nations (Labonte, Mohindra, \& Lencucha, 2011).

\subsection{Governance of State}

The process through which the states refrain or make from developing policies, develop context that causes insufficient polices and constrain the policy choices affected by TIAs.

\subsection{Developing Nations}

Generally, TIAs considerably affect the developing nations. Whereas, the inequalities in the wealth and income global distribution have many reasons, emerged from past practices that spread through serious wrong doings (Schram et al., 2018).

\subsection{Health Related Concerns}

For both communicable diseases and noncommunicable diseases (NCDs) factors, TIAs have direct consequences, that evolved from a basic issues between the health objectives and TIAs economic growth imperatives the communicable diseases facilitated by TIAs via people and products' international dissemination (Schram et al., 2018); TIAs also support the issues related to the resistance of antibiotic which are partially based on trade and the therapeutic drugs availability and affordability are effected by the laws of intellectual property. Further, NCDs are affected by TIAs as they form the environment in which the consumers/customers make decision on the product items like alcohol, foods and tobacco (Schram et al., 2018).

\section{DISCUSSION}

The above part formed a systemic, institutional and particular issues that the trade and investment agreements, in the context of their international governance, pose for objectives of public health. Different studies have recommended different approaches in which some of the TIAs negative implications can be solved (Thow et al, 2015). For reforming the investment treaties' development and execution, the United Nations Conference on Trade and Development has provided effective guidelines. The framework of their investment policy recommended the way to secure the rights of the states in order to enhance and regulate the procedures o dispute. For global health this particular article is established on these suggestions to provide a comprehensive and a systematic approach to change the TIAs (Mitchell \& Sheargold, 2015). It integrates a systematic framework for new law, determination of procedural, institutional and structural aspects that would be required to facilitate that frame work and also incoproates the general principles. The suggested approaches would not deny the international trade rules and its importance for regulations, but would propose a different TIAs that would acknowledge the different perspectives of common good (Thow \& McGrady, 2013).

\subsection{Health Nexus}

The execution of the WTO General Agreement on Trade in services (GATS), is the main concern of public health trade. In health services the trade is driven by different business considerations, not by the health services growth which generates reasonable results (Labonte, 2019). In most of the trade agreements, in health services the government that committed to trade can face difficulty to return to the financing or services related to public health care once they have been opened to the international competition and its privatisation. Similarly, the states where 
the service related to health care is financed or provided privately could easily stand to acquire via augmented access to the international market. The process of globalisation impacts the global health via different ways and not through the ways which are directly connected with the health system changes. Also, McNamara contribution is considered as the trade study persuasive example that endeavours to assess the trade policy reforms intersection regarding the social protection policies. For this work different articles have been collected and analysed (McNamara, 2018). It has ben identified that different into the health, trade and investment nexus different approaches yields insights, through building a connection among the investment and trade liberalisation agreements, specific outcome and trade policy.

\subsection{Agreements of WTO Related to Global Health}

In context, treaty processes and content in the international law frameworks regarding the development of trade and economy requires being changed considerably in order to meet the goals of public health effectively encompassing those connected to the Sustainable Development Goals (SGDs) of United Nations (Delany, Signal, \& Thomson, 2018). This study demonstrated that prevailing agreements of trade and investment have adverse implications on health. With this regard there was a requirement to stabilise and support the model treaties to get the effective outcomes. To secure the current chaos rerun because of the transparent, efficient, well-regulated and harmonised network of global healthcare, it is important for all nations to determine the gaps in the ecosystem of healthcare containing supply of goods and its production and service delivery and fill the gaps at both international and global level. This needs a coordinated and a systematic method on national level because healthcare different aspects come under the different departments and ministries jurisdiction containing welfare and wellbeing of family and health. Similarly, on global level there is a need for an updated integration among different agencies for instance the WTO, the UN, the WHO, the Food and Agricultural Organisation (FAO), International Telecommunication Union, World Intellectual Property Organisation (Kher \& Nair, 2020). This can assure healthcare services and products' smooth flow with less chances of disruptions during the global public health emergency like COVID-19 (Gruszczynski, 2020). It has been suggested the developing countries requires spending more time on the production of healthcare related goods and services.

\subsection{Non-Communicable Diseases and Trade and Investment Law}

In Globalisation and Health, different articles have been published to assess the agreements of trade and investment on the non-communication diseases (NCDs). Earlier studies took broad-bruised approach and assessing the current literature regarding the impacts of trade on the prevalence of $\mathrm{NCD}$, considerable in the countries which are low and middle-income that for the three unhealthy commodities represent new markets. Three commodities include alcohol, food and tobacco (Labonte, 2019). After assessing the main principles that govern all the rules and regulation of trade, expert constructed a broad framework determining how the rules and regulation of trade impact the unhealthy commodities' global distribution and finally both positive and negative outcomes of NCD. The mitigation and prevention strategies of NCD sustains to drive the disclosure of international health policy at different governance forums and at WHO precisely. On NCDs the high-level meeting of United Nations and commission continued to press in the year 2018 for the effective execution of the strategies to decrease the risk factors. In the literature related to public health, in spite the concern, less focus has been provided to the provision of investment and trade agreement as the augmented NCD mortality and morbidity's potential drivers (Labonte, 2019). 


\subsection{Essential Medicines Pricing}

In many countries of the world the trade related to healthcare service could enhance the care quality, but it can also augment the related services privatisation and for the low-income populations crowd-out the access. New discoveries of drugs can be stimulated by the intellectual property rights but for underdeveloped or poorer county price essential medicine beyond their affordability. With the possible trickle-down growth of income and linked benefits of healthcare the international trade can augment the growth of economy, but not every country can get equal benefit and within the nations the benefits may be inclined in some population's favour. To the level that the economic growth related to trade augments the environment externalities which are negative for instance resource depletion and climate change, it indirectly contributes to the augmented concerns of global health. To compliance with the global law of environment, the trade regulations could be employed and it could help to decrease the green technologies' diffusion barriers, also they can be employed to the underdeveloped nation's subsidies.

\subsection{Recommended Rules for TIAs}

The recommended framework and rules would be a respond to the identified issues posed by TIAs (mentioned in above section) (Labonte, 2019). For potential TIAs, to support the perspectives of common goods they would be employed as the benchmarks by the advocates of public health, relevant policy communities and treaty drafters. Principles' main aim is the succinct checklist provision for assessing from the perspective of global health. These proposed frameworks would facilitate the guide decisions regarding whether to renew TIAs, and of which type and in with which process accordance. The next aim of these frameworks is that, in some circumstances they could provide the notions for the inclusion in the text related to introductory treaty. These inclusions might be helpful in offering connections to other international laws. The below provided principles are divided into two different parts: appropriate to those procedures through which the treaties are established and those connecting to the treaty's objectives (Butler \& Subedi, 2017). Details will be provided in the further parts of the article.

\subsection{TIAs Development Procedures Framework}

The fundamental basis for the treaty procedures contains.

1. Considerable support for the nations and their citizen's effective participation and in these countries in creating sustainable strategies for TIAs, along with a precise emphasis to the nations which are underdeveloped and the poorer groups of population (Labonté, Schram, \& Ruckert, 2016).

2. Provide and effective support for the multilateralism approach, this method contains a commitment and devotion to the universality and openness norms preferably in the international governance institutions, structures and process and rule-based principles despite treaties which are regionally based.

3. Acknowledgement, during the process of treaty development, the need for effective utilisation and provision for the TIAs reviewed clauses (Labonté et al., 2016).

\subsection{TIA Objectives Principles}

A clear integration of human rights, environmental and social objectives as core to the TIAs and a considerable support for the Sustainable Development Goals or SDGs of United Nations, precisely those related to decreasing inequalities and redressing the imbalances power, eliminating the poverty factor, acknowledgement of the growth of economy for the objectives of common goods, advancing and securing the planetary health (the human civilisation health and supporting system of nature), redressing the harmed states' situation for example by providing differentiated and special treatment for the countries which are least developed, through international 
policies international corporations effective control by global community and support for the principles of human rights by integrating the human rights collective vision (Whitmee et al., 2015).

\subsection{Potential International Agreements Framework}

To plan new TIAs comprehensive approach has become important. This approach is a respond to the requirement to execute the sustainable development goals; and to endorse the global health in a way that do not put at risk the sustainability of the environment (Delany et al., 2018). The planetary or comprehensive approach for the TIAs plan, founded on the above-mentioned outline and would incorporate both social and environment objectives. Towards redesigning a new framework, the comprehensive approach would be strengthened by the treaty development enhanced procedures enabled in turn through the capacity of buttressed establishment. The new frameworks of TIAs would need for the effective governance support and execution from the appropriate global institution and the emphasis to concerns connected to the corporate behaviour significantly (Delany et al., 2018).

\subsection{Link between National and International Level}

In line with any identified disadvantages by the analyses of national interest or the assessment of health impact, the nation states with the help of their domestic law should counter identified TIAs negative impact. Such law needs to be implemented at the same time as the execution of the agreement (Gagliani, 2020). For instance, for disadvantaged group a compensatory taxation (for instance those who are unable to get their basic rights of treated well in the healthcare institutes) can be suitable. For the foreign direct investments (FDIs) the national law of the country needs contracts to acknowledge the national government responsibilities to regulated effective trade and investment law agreements for the health related issues. It also needs to be conditional on agreement with the explained environmental or health objectives for instance nutritional goals (Gagliani, 2020). The national law needs to specify that such condition's violation would lead to the possibility of the investor-state litigation invalidation.

\subsection{Applicability of TIAs Objectives}

In this article most of the notions provided were effectively projected in general terms in order to endorse the TIAs objectives of global health applicability as well as corporation's financial interest. At different phases, to assure such applicability the mechanism needs to occur; over a range of different policies in the TIAs; in other available legal policies which are related to the objectives of global or people health; in the national legislature and by any agreement regarding the businesses responsibilities with regards to the human rights. Whereas, ideally these mechanisms need to be interconnected, but they can also be executed independently.

\section{CONCLUSION}

To conclude, for the global health current TIAs have different negative consequences. Reconsidering the international governing trade law and the economic development current frameworks is possible and is important to acquire the objectives of public health and facilitate impact to the sustainable development goals. To the redesign and reconsideration of the interanion trade laws concerning to the global health different ideas have been provided to the comprehensive approach containing the integrated strategies and objectives to attain them and enhanced development of procedures and capacity. Global governance's considerable changes would facilitate the redesigning; and solve the specific issues (highlighted in the article) posed by the practices of TIAs. In international context the improvements and restructure of the TIAs needs to be reflected. Article also highlighted the issues like the law related to non-communicable diseases and trade and investment law. Discussion regarding this issue identified that 
the mitigation and prevention strategies of NCD sustains to drive the disclosure of international health policy at different governance forums and at WHO precisely. Also, the issues related to pricing of essential medicines have been incorporated. This issue highlighted that with the possible trickle-down growth of income and linked benefits of healthcare the international trade can augment the growth of economy, but not every country can get equal benefit. Some of these proposed ideas would be susceptible to the incremental approach. It is suggested to restructure the basic TIAs structure, as executed by the outlined comprehensive approach.

\section{REFERENCES}

Butler, N., \& Subedi, S. (2017). The future of international investment regulation: Towards a world investment organisation? Netherlands International Law Review, 64(1), 43-72. Available at: https://doi.org/10.1007/s40802-017-0082-5.

Canton, H. (2021). United Nations Conference on trade and development-UNCTAD. Paper presented at the InThe Europa Directory of International Organizations 2021 . Routledge.

Delany, L., Signal, L., \& Thomson, G. (2018). International trade and investment law: A new framework for public health and the common good. BMC Public Health, 18(1), 1-12. Available at: https://doi.org/10.1186/s12889-018-5486-6.

Gagliani, G. (2020). Cybersecurity, technological neutrality, and international trade law. Journal of International Economic Law, 23(3), 723-745. Available at: https://doi.org/10.1093/jiel/jgaaoo6.

Gruszczynski, L. (2020). The COVID-19 pandemic and international trade: Temporary turbulence or paradigm shift? European Journal of Risk Regulation, 11(2), 337-342. Available at: https://doi.org/10.1017/err.2020.29.

Kher, R., \& Nair, A. (2020). The case for a global healthcare partnership. Research and Information System for Developing Countries. India. 36-37.

Labonte, R. (2019). Trade, investment and public health: Compiling the evidence, assembling the arguments. Global Health 15(1), 1-12. Available at: https://doi.org/10.1186/s12992-018-0425-y.

Labonte, R., Mohindra, K. S., \& Lencucha, R. (2011). Framing international trade and chronic disease. Globalization and Health, $7(1), 1-15$

Labonté, R., Schram, A., \& Ruckert, A. (2016). The trans-pacific partnership agreement and health: Few gains, some losses, many risks. Globalization and Health, 12(1), 1-7. Available at: https://doi.org/10.1186/s12992-016-0166-8.

McNamara, C., \& Labonté, R. (2017). Trade, labour markets and health: A prospective policy analysis of the Trans-Pacific Partnership. International Journal of Health Services, 47(2), 277-297. Available at: https://doi.org/10.1177/0020731416684325.

McNamara, C. (2018). Is trade policy a missing piece to a public health puzzle? Global Social Policy, 18(1), 81-87. Available at: https://doi.org/10.1177/1468018117748699.

Mitchell, A., \& Sheargold, E. (2015). Protecting the autonomy of states to enact tobacco control measures under trade and investment agreements. Tobacco Control, 24(e2), e147-e153. Available at: https://doi.org/10.1136/tobaccocontrol2014-051853.

Puig, S. (2015). The merging of international trade and investment law. Berkeley Journal of International Law, 33 (1), 1-20.

Schram, A., Ruckert, A., VanDuzer, J. A., Friel, S., Gleeson, D., Thow, A.-M., \& Labonte, R. (2018). A conceptual framework for investigating the impacts of international trade and investment agreements on noncommunicable disease risk factors. Health Policy and Planning, 33(1), 123-136. Available at: https://doi.org/10.1093/heapol/czx 133.

Thow, A. M., \& McGrady, B. (2013). Protecting policy space for public health nutrition in an era of international investment agreements. Bulletin of the World Health Organization, 92(2), 139-145. Available at: https://doi.org/10.247 1/blt.13.120543. 
Thow, A., Snowdon, W., Labonté, R., Gleeson, D., Stuckler, D., Hattersley, L., \& Friel, S. (2015). Will the next generation of preferential trade and investment agreements undermine prevention of noncommunicable diseases? A prospective policy analysis of the trans pacific partnership agreement. Health Policy and Planning, 119(1), 88-96. Available at: https://doi.org/10.1016/j.healthpol.2014.08.002.

Whitmee, S., Haines, A., Beyrer, C., Boltz, F., Capon, A. G., de Souza Dias, B. F., \& Head, P. (2015). Safeguarding human health in the Anthropocene epoch: Report of the rockefeller foundation-lancet commission on planetary health. The Lancet, 386(10007), 1973-2028.

Online Science Publishing is not responsible or answerable for any loss, damage or liability, etc. caused in relation to/arising out of the use of the content. Any queries should be directed to the corresponding author of the article. 